\title{
La utilización de la constitución vigente como freno a grandes transformaciones políticas. Los casos de Venezuela, Bolivia, Ecuador y el reciente caso de Catalunya en el Reino de España*
}

\author{
Using the Constitution Currently in Force as a Hindrance to Large Political Transformations. The Cases in \\ Venezuela, Bolivia, Ecuador and the Recent Case of Catalonia in the Spanish Kingdom
}

\author{
Eneko Compains Silva ${ }^{\text {a }}$ \\ Universidad Del Pais Vasco, España \\ eneko.compains@ehu.eus \\ ORCID: https://orcid.org/0000-0002-3283-6879
}

DOI: https://doi.org/10.11144/Javeriana.papo25.ucvf

Recibido: 04 Septiembre 2018

Aceptado: 03 Abril 2019

Publicado: 29 Junio 2020

\section{Resumen:}

Como es sabido, Catalunya se encuentra inmersa en pleno proceso soberanista. Desde hace años, una mayoría social, política e institucional promueve dicho proceso con el objetivo de fundar una república catalana independiente. Desde Madrid, el Gobierno de España trata de frenar dicho proceso, pero para ello, en vez de utilizar herramientas habituales en política como el diálogo, la negociación y el acuerdo, se empeña en acudir al Tribunal Constitucional para que este, Constitución en mano, prohíba o anule las distintas decisiones que una mayoría democrática en Catalunya viene aprobando. Es decir, parece que se utiliza continuamente la Constitución vigente para frenar en los Tribunales lo que no se puede frenar con votos en las instituciones de Catalunya. ¿Es realmente así?, ¿ es legítimo hacer esto?, ¿existen casos similares? Salvando las distancias, a priori parece algo similar a lo que ya ha ocurrido en el caso de otras grandes transformaciones políticas, como lo fueron los procesos constituyentes de Venezuela, Bolivia y Ecuador. El presente trabajo pretende analizar todos esos casos, tanto en su vertiente política como en la jurídica.

Palabras clave: constitución, poder constituyente, democracia, transformación política, Latinoamérica, Catalunya.

\section{Abstract:}

As already known, Catalonia is currently undergoing a sovereignty issue. A social, political and institutional majority is encouraging a sovereignty process from some years ago to date, in order to found an independent Catalonian Republic. Based in Madrid, Spanish Government is trying to stop such a process, but they are not using the usual tools in politics such as the dialogue, negotiation, and covenants. Instead, they are resorting to the Constitutional Court so that this court —on the grounds of the Constitution — annul or prohibit the different decisions made by a democratic majority in Catalonia. It seems that they in Madrid are using continuously the Constitution in force to hinder in the courts what they cannot stop with the votes in the Catalonian institutions. Is this actually true? Would it be legitimate to act this way? Are the some other similar cases? Differences aside, it seems a priori similar to the case that has already occurred in other large political transformations, such as the constituent process in Venezuela, Bolivia and Ecuador. This work aims to analyze all these cases, both in the political and the legal fields.

Keywords: constitution, constituent power, democracy, political transformation, Latin America, Catalonia.

\section{Introducción}

El 31 de agosto de 2017, el periódico La Vanguardiallevaba a su portada un contundente titular: "El Gobierno prepara con el TC una suspensión exprés”. El titular hacía referencia a la suspensión de las leyes de referéndum y de transitoriedad jurídica (Comunidad Autónoma de Cataluña, 2017a, 2017b) que estaban próximas a aprobarse en el Parlament de Catalunya en aquellos días (leyes que fueron primero suspendidas y más tarde derogadas por el Tribunal Constitucional).

Si se lee con atención el titular, se puede comprobar que habla muy mal de la neutralidad e independencia que supuestamente debiera tener el TC con base en el artículo 159.5 de la Constitución Española (en adelante

Notas de autor

a Autor de correspondencia. Correo electrónico: eneko.compains@ehu.eus 
CE), si bien resume de forma meridianamente clara la estrategia del Gobierno español (Gobierno de España, 1978) en relación con Catalunya ${ }^{1}$.

Como es sabido, Catalunya se encuentra inmersa en pleno proceso soberanista. Desde hace años, una mayoría social, política e institucional viene promoviendo dicho proceso con el objetivo de fundar una república catalana independiente, combinando grandes movilizaciones de masas y procesos participativos con la aprobación de todo tipo de resoluciones y legislación en el Parlament de Catalunya, e incluso, la celebración de un referéndum de autodeterminación el 1 de octubre de 2017, fecha que sin lugar a dudas ha quedado grabada en la historia reciente de Catalunya.

Desde Madrid, el Gobierno central intenta frenar dicho proceso, pero para ello, en lugar de utilizar el diálogo, la negociación o el acuerdo, prefiere acudir al Tribunal Constitucional para que este, Constitución en mano, prohíba o anule las distintas decisiones que una mayoría democrática en distintas instituciones de Catalunya viene aprobando. Es decir; en lugar de utilizar herramientas políticas ante un problema político (como se hizo, por ejemplo, en el Reino Unido con Escocia en $2014^{2}$ ), el problema se judicializa, se lleva a los Tribunales como si de una simple cuestión legal o jurídica se tratase.

En definitiva, parece que se utiliza la Constitución vigente para frenar un proyecto político democrático como es la independencia de Catalunya, por la sencilla razón de que los contrarios a la misma no pueden frenarla en las instituciones representativas de dicha nación (al estar en minoría). Es decir, se judicializa una cuestión radicalmente política y se busca frenar en los Tribunales lo que no se puede parar con votos o con negociación. ¿Es esto lo que en definitiva está sucediendo?, ¿es legítimo que así sea?, ¿ha sucedido en otros lugares previamente?

A priori, y salvando las obvias distancias, parece algo similar a lo que ya ocurrió, por ejemplo, en los procesos constituyentes latinoamericanos de la primera década del siglo XXI: Venezuela (1999-2000), Bolivia (2005-2009) y Ecuador (2007-2008)3, donde las élites políticas y económicas de la época, que pretendían conservar el sistema y evitar grandes transformaciones sociopolíticas, al estar en minoría, acudieron continuamente a los respectivos Tribunales Constitucionales (o sus equivalentes) para tratar de frenar dichas transformaciones.

Incluso en el caso de la convocatoria a una "constituyente ciudadana" en Venezuela, el pasado 2017, podríamos encontrarnos ante un fenómeno similar, donde la oposición al chavismo, con mayoría en la Asamblea Nacional, trató de frenar dicha convocatoria en el Tribunal Supremo de Justicia (TSJ).

El presente trabajo pretende hacer un análisis de dichos procesos, tanto en su vertiente política como jurídica, para poder dar respuesta a las preguntas que se acaban de formular.

\section{El proceso constituyente en Venezuela (1999-2000)}

El proceso constituyente de 1999 en Venezuela fue toda una "disidencia histórica" en la historia de esta república, ya que el tránsito del viejo al nuevo sistema político no se hizo, como en el pasado, mediante la violencia, sino de forma absolutamente pacífica, fruto de una elección democrática y popular (Brewer-Carías, 1999, pp. 16-17). Sin embargo, el hecho de que fuese pacífico no significó que fuese carente de polémica y conflicto.

Chávez había ganado las elecciones presidenciales de diciembre de 1998, y prometido la convocatoria inmediata de una Asamblea Constituyente que permitiese refundar la república y establecer una democracia social y participativa. Quería hacer una revolución, no una simple reforma (Garrido, 1999, p. 175). Frente a él, los defensores del statu quo de entonces (anclado en la Constitución de 1961), no querían ni oír hablar de dicha idea, pero conscientes de su falta de legitimidad social y capacidad para frenar políticamente la iniciativa, decidieron judicializar la batalla presentando a lo largo de todo el proceso, y de forma continuada, recursos 
ante los Tribunales de justicia. Es decir, aunque el problema era eminentemente político, prefirieron acudir a los Tribunales.

Los dos primeros recursos fueron de interpretación, a través de los cuales se solicita al Tribunal que aclare o concrete la interpretación de una norma de rango legal o constitucional.

El debate constitucional fundamental era que la Constitución de 1961 (Gobierno de Venezuela, 1961) no regulaba la posibilidad de convocatoria de una Asamblea Constituyente como mecanismo para aprobar una nueva Constitución; tan solo regulaba la posibilidad de enmienda (art. 245) y la reforma general (art. 246). Ambos procesos eran muy rígidos y difíciles de llevar a la práctica, y eran, además, dependientes del Congreso y de las cámaras legislativas territoriales, donde seguían siendo mayoría los partidos políticos tradicionales, que en el pasado habían dado sobrada muestra de su incapacidad para llevar a cabo las reformas que el país necesitaba (Márquez Ferrer, 1998, p. 24).

Por ello, sabedores de que no se podían oponer abiertamente a una Asamblea que contaba con amplio respaldo popular, lo que plantearon fue encerrarla en la legislación constitucional vigente. Ya lo habían hecho en el pasado.

Así, descartando la posibilidad de una Asamblea Constituyente originaria, defendieron que se debían respetar los mecanismos de reforma de la Constitución de 1961. En su opinión, la única vía valida era incorporar un nuevo artículo que regulase la Asamblea constituyente como un nuevo mecanismo de reforma constitucional.

Como ya se ha dicho, eso en el pasado había resultado imposible, por lo que distintos autores se preguntaron: si el Congreso llevaba años debatiendo sin ningún tipo de resultado distintos proyectos de reforma, ¿qué sentido tenía hacer pasar las posibilidades de cambio por dicha institución?

No cabía esperar otra cosa que el sabotaje a la iniciativa (Romero Jiménez, 2002), así que la estrategia del chavismo fue otra. Se trataba de encontrar herramientas legales para arreglar una cuestión política, no para añadir problemas. Se trataba, en definitiva, de facilitar y no obstruir dicha convocatoria mayoritariamente deseada por la sociedad, apelando directamente a la soberanía del pueblo.

Para ello propusieron descartar la vía de la reforma y activar el poder constituyente originario. ¿Cómo? Valiéndose del art. 4 de la Constitución y el art. 181 de la Ley Orgánica de Sufragio y Participación Política (Gobierno de Venezuela, 1998), que establecían la soberanía popular y la posibilidad del presidente de consultar al pueblo sobre cuestiones de especial trascendencia nacional. Es decir, la vía para llegar a la Asamblea Constituyente sería la celebración de un referéndum consultivo en el que el pueblo decidiría directamente si quería o no Asamblea Constituyente.

Al final, la polémica se dirimió en la Corte Suprema de Justicia de Venezuela que, el 19 de enero de 1999, emitió dos sentencias que avalaron la vía chavista a la constituyente de forma muy clara (Corte Suprema de Justicia de Venezuela, 1999a). Estas establecieron que el hecho de regular las posibilidades de reforma en una Constitución no agotaba las posibilidades de activar libremente el poder constituyente originario, ya que, de ser esto así, los diputados dejarían de ser los representantes del pueblo soberano para convertirse en los representantes soberanos del pueblo. La soberanía residía en el pueblo, no en sus representantes.

Para el Alto Tribunal, de ninguna manera se podían confundir el poder de reforma y el poder constituyente originario, ya que se trataba dos operaciones bien diferentes. Mientras el primero estaba en manos de los poderes constituidos, y significaba una operación jurídica con límites legales y no podía cambiar los elementos esenciales de la Constitución, el segundo era un poder originario, de carácter político y completamente libre. Tenía supremacía sobre los poderes constituidos y sobre el conjunto del ordenamiento jurídico vigente.

El poder constituyente, dijo la Corte, no nacía del ordenamiento jurídico vigente, sino que era su fundamento; nacía directamente de la soberanía popular. Por ello, la previsión del art. 250 que establecía que la Constitución no perdería su vigencia si fuese derogada o reformada por vías distintas a las previstas, era un mandato dirigido a los poderes constituidos y no al titular del poder constituyente originario: el pueblo. 
Con base en estas sentencias, se pudo celebrar el referéndum constituyente y desarrollar el proceso, no sin dificultades. Como se ha dicho, la oposición judicializó una y otra vez la disputa política para intentar frenar y obstaculizar cada paso (puso recursos contra las bases del referéndum, la convocatoria a elecciones, etc.). Hubo varias sentencias contradictorias con las dos primeras, que pretendieron atar la Asamblea Constituyente a la Constitución de 1961 (Gobierno de Venezuela, 1961), eliminando toda referencia a su carácter originario en las bases comiciales. Sin embargo, la Asamblea, una vez instalada, proclamó por boca de su presidente, Luis Miquilena, su carácter irremisiblemente originario (Gaceta Constituyente, 1999).

Valiéndose de dicho carácter, aprobó, además, tres decretos que limitaban las facultades de los poderes constituidos (legislativo y judicial), para poder así reordenar las estructuras del Estado y desarrollar sin obstáculos la labor constituyente, lo cual generó un enfrentamiento fuerte sobre todo con el Congreso de la República. Su presidente, Henrique Capriles, acudió a los Tribunales alegando que estaban siendo violados sus derechos como diputado, pero lo cierto es que estos terminaron por darle la espalda. Así, fue de nuevo la Corte Suprema de Justicia, esta vez en pleno, quien dirimió la disputa fallando a favor de los promotores del proceso y ratificando el carácter originario y supremo de la Asamblea (Corte Suprema de Justicia de Venezuela, 1999b).

Según la Corte, por encima de los poderes legislativo, ejecutivo y judicial había un poder supremo que tenía como misión establecer el resto de poderes, por lo que, en buena lógica, había de distinguirse de ellos. Ese poder era el constituyente, "la facultad suprema con la que cuenta un pueblo para darse un ordenamiento jurídico o cambiarlo cuando lo juzgue necesario" (Corte Suprema de Justicia de Venezuela, 1999b).

La Asamblea pudo así culminar su labor y aprobar finalmente un proyecto de Constitución (Gobierno de Venezuela, 1999) que fue ratificado por el pueblo, en el referéndum, del 15 de diciembre de 1999.

\section{El proceso de cambio constitucional en Bolivia (2006-2009)}

En Bolivia, la victoria electoral de Evo Morales en las elecciones presidenciales de diciembre de 2005 fue posible solo porque previamente había habido un ciclo importantísimo de movilizaciones sociales en el país, que profundizaron en la crisis de legitimidad del sistema y fueron configurando una agenda política para el cambio. Dicho ciclo fue bautizado como el "ciclo rebelde" (Errejón Galván, 2009, p. 24).

Todo empezó como una simple lucha sectorial en defensa del agua en Cochabamba, allá por el año 2000 (conocida como "Guerra del Agua"). Sin embargo, con el paso del tiempo se dio paso a un movimiento que fue agregando distintos sectores sociales, y configurando una agenda con base en tres reivindicaciones: nacionalización de hidrocarburos, Asamblea Constituyente y enjuiciamiento del presidente de la República (Sánchez de Lozada).

Vista la importancia de las movilizaciones, para febrero de 2004 al Congreso no le quedó otra opción que modificar la Constitución y recoger la figura de la Asamblea Constituyente (Gobierno de Bolivia, 2002, 2004), para cuya convocatoria el Congreso de la República debía aprobar una ley especial por mayoría de dos tercios (art. 232).

Sin embargo, hay que decirlo, la Asamblea Constituyente no se recogió como depositaria del poder constituyente originario del pueblo, sino como una institución reformadora especial que pudiera llevar a cabo la reforma general de la Constitución. Y esto tiene su importancia, ya que, de esta manera, la Asamblea quedaba atada a la Constitución de 1967 (Gobierno de Bolivia, 1967), por lo menos si se apostaba por la vía prevista en esta para su convocatoria.

¿Qué implicaciones tuvo la aprobación de esta reforma? Grandísimas. Básicamente porque al ser necesaria una mayoría de dos tercios de la cámara para la aprobación de la ley de convocatoria (Gobierno de Bolivia, 2006), hubo que negociar y transigir, y así, la oposición al proceso de cambio, aun estando en amplia minoría, fue capaz de introducir en dicha ley el imperativo de que la Asamblea Constituyente adoptase las decisiones 
por mayoría de dos tercios. Es decir; aun perdiendo las elecciones, en la práctica se garantizaban un derecho de veto ${ }^{4}$.

$\mathrm{Si}$, por el contrario, la convocatoria hubiera sido como en Venezuela, fruto de un acto directo de soberanía por parte del pueblo (vía referéndum), la cosa podría haber cambiado, porque hubiese sido el presidente Morales quien hubiese propuesto las bases de la Asamblea Constituyente, y el pueblo quien las habría ratificado.

Cierto es que ya en 2001 el Tribunal Constitucional boliviano había cerrado las puertas a dicha posibilidad en respuesta a una cuestión de constitucionalidad planteada por el presidente del Congreso, alegando que la misma no estaba prevista en la Constitución (Tribunal Constitucional de Bolivia, 2001). Es decir, el Alto Tribunal de Bolivia razonó a la inversa que lo había hecho el de Venezuela.

Con base en la ley de convocatoria mencionada fue que se celebraron las elecciones a la Asamblea Constituyente, elecciones en las que el MAS obtuvo la mayoría absoluta de votos (50,8\%), dejando a la segunda fuerza, Podemos, a más de 35 puntos de distancia. En cuanto a escaños, el sistema electoral hizo que fuesen 137 representantes frente a 60 , quedando el resto de fuerzas muy por detrás, con entre uno y 8 representantes.

Lo más relevante de todo fue que como no hubo mayoría de dos tercios para el MAS, hubo que negociar el funcionamiento de la Asamblea con aquellas fuerzas que se oponían al proceso de cambio, lo cual hizo que este se dilatase mucho en el tiempo (más de dos años y medio). La oposición (Podemos, sobre todo) exigió en el debate sobre el reglamento de funcionamiento de la Asamblea que fuese necesaria una mayoría de dos tercios hasta para la más pequeña de las decisiones, aunque al final no lo consiguió del todo. Para algunos autores fue un verdadero "chantaje" (De La Fuente, 2008, pp. 85-100).

Además, al no ser una Constituyente originaria, fue imposible establecer su supremacía sobre el resto de poderes constituidos, lo cual tuvo nuevas consecuencias. Así, aun cuando la ley de convocatoria decía que el texto final sometido a referéndum sería el que saliese de la Asamblea (art. 26), finalmente no fue así.

Por el contrario, hubo que emplear buena parte del año 2008 en negociar con la oposición en el marco de una comisión compuesta por senadores y congresistas de MAS, Podemos, UN y MNR; comisión que enmendó más de 100 artículos del proyecto de Constitución aprobado por la Constituyente.

Como la legalidad de dicha operación era muy dudosa, hubo de aprobarse una ley que certificase aquel fraude; ley que permitía al Congreso "ayudar" en el proceso, pudiendo alterar el texto propuesto por la Asamblea, "respetando siempre el interés nacional y sin afectar a la esencia de la voluntad constituyente" (Gobierno de Bolivia, 2008a) ${ }^{5}$. Se hizo, por cierto, el mismo día en que se aprobó la Ley de Referéndum de la Constitución (Gobierno de Bolivia, 2008b) ${ }^{6}$, que aprobaba todos los cambios introducidos por el Congreso y convocaba una consulta ciudadana para el 25 de enero de 2009, consulta en la que el pueblo ratificó, por amplia mayoría, la nueva Constitución Política del Estado (Gobierno de Bolivia, 2009).

\section{El proceso constituyente en Ecuador (2007-2008)}

$\mathrm{Al}$ igual que Bolivia, Ecuador vivió una profunda crisis política, económica e institucional a comienzos de los 2000 (distintos autores hablan de un sistema "completamente colapsado" [Echeverría, 2007, p. 28] y en "estado de descomposición" [Pérez-Loose, 2009, p. 241]). De hecho, no hay más que ver que entre 1996 y 2006 fueron derrocados nada menos que 3 presidentes, hubo 8 gobiernos, fueron cesadas 4 Cortes Supremas y 3 Tribunales Constitucionales. Es decir, no hubo poder estatal que terminase su mandato con normalidad (Ávila Santamaría, 2008, pp. 92-93).

Ante esa situación, la necesidad de reformar el sistema se imponía, y así lo intentó el presidente Palacio en 2005. La Constitución de 1998 (Gobierno del Ecuador, 1998) no preveía expresamente la posibilidad de convocar una Asamblea Constituyente (los arts. 280-284 regulaban la reforma), así que optó por lo que 
podríamos llamar "vía venezolana". El 17 de octubre aprobó por decreto (Gobierno del Ecuador, 2005a) la convocatoria a una consulta sobre la Asamblea Constituyente, basándose en el art. 104 de la Constitución que permitía al presidente consultar a la ciudadanía sobre temas de especial trascendencia nacional.

Sin embargo, el Tribunal Supremo Electoral (en adelante TSE) no adoptó la misma posición que la Corte Suprema de Justicia de Venezuela, y emitió una resolución rechazando la petición del presidente de que se organizase la consulta. En su opinión, la Constitución de 1998 no facultaba al presidente para organizar tal consulta y, en consecuencia, declaró el decreto inaplicable (Gobierno del Ecuador, 2005b).

El presidente, sin embargo, no se dio por vencido, y el 30 de noviembre emitió un nuevo decreto (Gobierno del Ecuador, 2005c) en el que exigía (no solo solicitaba) al TSE que organizase la consulta para el 22 de enero de 2006. El TSE, por el contrario, se mantuvo en su posición y rechazó el mandato recibido, negándose a organizar el referéndum (Gobierno del Ecuador, 2005d). Lo cierto es que las decisiones del TSE, y especialmente su argumentación, generaron muchísimas dudas entonces (Pérez-Loose, 2009, p. 242), especialmente por la vinculación que dicha institución tenía con los partidos políticos tradicionales. De hecho, según Muñoz López (2006), lo que ocurrió fue que los “dueños del país" quisieron obstaculizar toda posibilidad de cambio, y en aquel entonces todavía tuvieron capacidad para hacerlo, ya que seguía vigente la "partidocracia" por la que primaban los intereses corporativos de las clases dominantes.

Sin embargo, la cosa cambió a los pocos meses con la victoria electoral de Correa en las elecciones presidenciales del 15 de octubre de 2006. Su propuesta era radicalmente favorable a una Asamblea Constituyente con "plenos poderes", y aunque su propuesta fue tildada de "maximalista", no tardó en desarmar a quienes usaban argumentos más "procedimentalistas” y defendían que la consulta se hiciese, pero para fijar los temas a tratar en el Congreso. Para esto últimos, la Asamblea Constituyente no era sino una simple opción ante un eventual fracaso del debate en el Congreso (Echeverría, 2007, pp. 29-30).

Por el contrario, Correa y Alianza País ni siquiera presentaron candidatos al Congreso. Llamaron a anular el voto en las elecciones legislativas, porque consideraban a dicha institución el punto de reunión de la vieja política, y porque no quisieron hacerles el juego a las viejas prácticas políticas de la "partidocracia" (Salgado Pasantes, 2009).

El 15 de enero de 2007, una vez ganadas las elecciones presidenciales, Correa juró el cargo. No lo hizo sobre la Constitución de 1998 (hecho muy significativo) y, además, en su discurso de toma de posesión dejó bien claro que el primer eje de la Revolución Ciudadana era una revolución constitucional (Ávila Santamaría, 2011, p. 120; Aguiar de Luque y Reviriego Picón, 2006).

Ese mismo día, siguiendo los pasos de su predecesor Alfredo Palacio, firmó el decreto de convocatoria a un referéndum sobre la Asamblea Constituyente (Gobierno del Ecuador, 2007a): “¿Aprueba usted que se convoque e instale una Asamblea Constituyente con plenos poderes, de conformidad con el estatuto electoral que se adjunta, para que transforme el marco institucional del Estado y elabore una nueva Constitución?”.

El tema de los plenos poderes de la Asamblea y de qué ocurriría, tanto con el ordenamiento jurídico vigente como con los poderes constituidos durante el proceso, generó controversia y debate, incrementando mucho la tensión política aquellos días.

El 22 de enero, el presidente del TSE se vio en la necesidad de aclarar el rol del Tribunal. Su papel no sería juzgar la constitucionalidad de la convocatoria, sino la viabilidad de cumplirla. Así, al día siguiente, en decisión muy ajustada (4 contra 3) y controvertida, decidió enviar todo el expediente al Congreso, para que este decidiese si se estaba respetando el art. 283 de la Constitución (o no) y tomase una decisión sobre la consulta.

Esto generó gran enfado en el Gobierno (ya que el Congreso estaba exclusivamente en manos opositoras), aunque matizaron que para ellos tan solo se trataba de una consulta, y organizarla era una obligación del TSE según el art. 104 de la Constitución (Brewer-Carías, 2009, pp. 465-466). 
Sea como fuere, días más tarde el presidente emitió un nuevo decreto (Gobierno del Ecuador, 2007b) que modificaba el estatuto electoral de la convocatoria a la Asamblea, y comunicó al Congreso que se respetarían todas las normas, para que este no pusiese trabas a la convocatoria.

La tensión fue en aumento los siguientes días, con miles de personas frente al Congreso exigiendo la convocatoria, pero el Congreso no terminaba de responder. Visto que los plazos se dilataban, el 12 de febrero Correa hizo unas declaraciones diciendo que, si el problema no lo solucionaban entre el TSE y el Congreso, organizaría un Tribunal ad hoc, donde dejó claro que no daría marcha atrás en la cuestión de los plenos poderes de la Asamblea que la oposición quería eliminar para no poner en riesgo la "partidocracia".

Finalmente, el día 13 el Congreso dio luz verde a la consulta (introduciendo algunas modificaciones), y escenificó así que se subía al "tren constituyente" (Congreso Nacional del Ecuador, 2007a). No le había quedado otra opción, ante la tremenda popularidad de la iniciativa (Pérez-Loose, 2009, p. 247).

De todas formas, varios miembros del TSE declararon aquellos días que las modificaciones del Congreso no eran más que "recomendaciones" que solo serían válidas si las aceptaba el presidente, ya que se trataba de una iniciativa suya. Y así lo ratificó el propio Correa, que dijo que la consulta estaba sobre el tejado del Tribunal y no sobre el Congreso. El poder constituyente trabajaría sobre la base de que residía en el pueblo (y no en sus representantes ordinarios, se entiende) (Pérez-Loose, 2009, p. 247).

Finalmente, el presidente aprobó un nuevo decreto haciendo unas últimas modificaciones en el estatuto electoral de convocatoria a la Asamblea Constituyente, y con base en el mismo, el TSE organizó la consulta ciudadana. Resulta cuanto menos sorprendente, ya que el mismo órgano había negado dicha posibilidad hasta en dos ocasiones al presidente Palacio.

La oposición, en todo caso, no se quedó quieta, y continuó con su estrategia obstruccionista, aunque esta vez ya sin ninguna base legal mínimamente discutible. Primeramente, intentaron presionar al Tribunal, pero a falta de resultados, aprobaron una declaración (Congreso Nacional del Ecuador, 2007b), totalmente inconstitucional, en la que destituían a 4 de los 7 miembros del TSE (Pérez-Loose, 2009, p. 249). Ni la Constitución ni la ley preveían una medida así.

El TSE se defendió, y además lo hizo de forma contundente. Los miembros del Tribunal rechazaron ser sustituidos y tacharon la declaración del Congreso de inaplicable. Pero no solo eso. Con base en artículo 155 de la Ley Orgánica de Elecciones (Gobierno del Ecuador, 2000), ${ }^{7}$ el TSE consideró que los diputados que votaron por la resolución del Congreso habían entorpecido un proceso electoral en curso, por lo que los destituyó de su cargo.

La medida encontró oposición en buena parte de la doctrina, aduciendo que la norma aplicada iba dirigida a autoridades o funcionarios de bajo nivel, y no a las autoridades políticas, por lo que se trataba, decían, de un acto de fuerza (Salgado Pasantes, 2009). También se dijo que el TSE carecía de atribuciones para adoptar dicha medida, y que los diputados habían sido expulsados sin juicio previo (Pérez-Loose, 2009, pp. 249-250). Lo cierto es que la medida fue eficaz; que a los diputados destituidos se les impidió entrar al Congreso y que fueron nombrados sus suplentes, con los que parece que el Gobierno pudo llegar a algún entendimiento y cerrar la crisis.

Mientras, eso sí, los diputados destituidos acudieron a los Tribunales. En primera instancia no tuvieron suerte, ya que su pretensión fue desestimada aduciendo que, estando en periodo electoral, las decisiones del TSE no se podían revisar. Sin embargo, acudieron entonces al Tribunal Constitucional, y este sí les dio la razón, revocó la sentencia de primera instancia (alegando que la resolución del TSE era inconstitucional) y ordenó que los diputados volviesen a sus puestos.

Sin embargo, para entonces ya se habían nombrado diputados suplentes, se había celebrado el referendo y, por si eso fuera poco, las actas de aquella sesión del TC desaparecieron en unos sucesos poco claros (Salgado Pasantes, 2009).

Además, como el mandato de los magistrados del TC estaba vencido, el Gobierno no aceptó la resolución del Alto Tribunal. Los nuevos diputados destituyeron a los magistrados del TC, que estuvo descabezado 
hasta el 31 de mayo, día en que el Congreso cubrió las vacantes. Días más tarde, los nuevos magistrados dejaron sin efecto la resolución de sus predecesores y mantuvieron vigente la decisión del TSE, de forma que el proceso constituyente pudo continuar su curso. El pueblo ecuatoriano dio un amplio respaldo al mismo y le abrió las puertas a una Asamblea Constituyente con "plenos poderes”, que encontró pocos obstáculos en el ordenamiento jurídico vigente y en los poderes constituidos para poder desarrollar su labor. La nueva Constitución fue ratificada en referéndum el 28 de septiembre de 2008.

\section{Venezuela: la convocatoria a una constituyente "ciudadana" (2017)}

Como es por todos sabido, Venezuela atraviesa desde hace tiempo una situación de grave crisis política, económica, social e institucional, que ha hecho que la tensión política en el país haya subido mucho durante los últimos años. Basta con ver la oleada de violentas protestas que se desató en el país en los primeros meses de 2017.

Los factores que explican la crisis son muy diversos: algunos exógenos, como la caída de los precios internacionales del petróleo, que golpea fuertemente la principal vía de ingreso de divisas. Otros endógenos y achacables (por lo menos en parte) al chavismo: problemas de eficiencia en la administración, distintos errores en los programas sociales, la corrupción y la falta de mayor eficacia en su combate, la incapacidad (hasta la fecha) para poner en marcha un nuevo modelo productivo, etc. Por último, y probablemente más importante, la estrategia golpista y desestabilizadora de una oposición que cuenta con el apoyo de EE. UU., y que parece aceptar que todavía no ha ganado las elecciones presidenciales en un país que tiene un sistema de gobierno presidencialista.

En la estrategia desestabilizadora de la oposición se podrían distinguir varios puntales: la guerra económica, es decir, desabastecimiento programado, inflación inducida y acoso financiero internacional (Curcio Curcio, 2017), donde se destacan las sanciones de la Administración Trump (EE. UU.); la búsqueda del aislamiento internacional de la república, a nivel diplomático sobre todo; la mentira y manipulación con ayuda del oligopolio mediático mundial; el desafío a los poderes legítimos de la república (ejecutivo y judicial sobre todo); y la violencia en las calles de Venezuela, con el objeto de precipitar una intervención militar extranjera (solicitada por algunos representantes opositores) o un golpe de Estado por parte de militares venezolanos (Peláez, 2017; Katz, 2017).

Ante esta situación, y viendo que resultaba imposible solucionar la crisis empleando los poderes ordinarios del Estado, el 1 de mayo de 2017, el presidente Maduro consideró que lo mejor sería convocar a un poder extraordinario: el poder constituyente del pueblo. Es decir, en lugar de optar por la fuerza, optó por la vía democrática, consultando al pueblo soberano. Su objetivo: articular un diálogo nacional que asentase primero un escenario de paz y pusiese después las bases para solucionar los distintos problemas sociales, políticos y económicos que atraviesa el país.

Para ello, se valió del artículo 348 de la Constitución de Venezuela (Gobierno de Venezuela, 1999), que le otorgaba la iniciativa para la convocatoria a una Asamblea Constituyente. La oposición, en los años y meses precedentes, había hablado de que, si no había referéndum revocatorio, la convocaría ella misma (la Asamblea Nacional lo puede hacer, igual que el presidente, con base en mismo artículo), pero al proceder la iniciativa de Nicolás Maduro, la rechazaron ipso facto. No les gustó la forma de elección propuesta (por territorio y por sectores sociales) ni el modo de convocatoria ( además de desatar la violencia en las calles, acudieron, como en el pasado, a los Tribunales.

En concreto, pidieron que se aclarase el significado de los artículos 347 y 348 de la Constitución, convencidos de que no se podía convocar dicha Asamblea si no era mediante un referéndum aprobatorio por parte del pueblo, tal y como se había hecho en 1999.

Los artículos mencionados dicen lo siguiente: 
Artículo 347: el pueblo de Venezuela es el depositario del poder constituyente originario. En ejercicio de dicho poder, puede convocar una Asamblea Nacional Constituyente con el objeto de transformar el Estado, crear un nuevo ordenamiento jurídico y redactar una nueva Constitución.

Artículo 348: la iniciativa de convocatoria a la Asamblea Nacional Constituyente podrán tomarla el Presidente o Presidenta de la República en Consejo de Ministros; la Asamblea Nacional, mediante acuerdo de las dos terceras partes de sus integrantes; los Consejos Municipales en cabildo, mediante el voto de las dos terceras partes de los mismos; o el quince por ciento de los electores inscritos y electoras inscritas en el registro civil y electoral. (Gobierno de Venezuela, 1999)

La Sala Constitucional del Tribunal Supremo de Justicia resolvió la duda al dar la razón al presidente, y estableciendo que la iniciativa era constitucional (Tribunal Supremo de Justicia de Venezuela, 2017). Lo hizo con base en cuatro principales argumentos:

En primer lugar, el Tribunal dijo que, si en 1999 hubo que consultar al pueblo sobre la convocatoria a una Constituyente, fue porque la antigua Constitución de 1961 no preveía la posibilidad de dicha convocatoria, cosa que es cierta:

En relación a la interpretación requerida, debemos inicialmente recordar que la Constitución de 1961 no contemplaba en su Título X (De las Enmiendas y Reformas a la Constitución), la figura de la Asamblea Constituyente para que el pueblo, como poder constituyente originario, pudiera redactar un nuevo texto fundamental....De lo expuesto se evidencia que el proceso constituyente que dio a luz la vigente Constitución de la República Bolivariana de Venezuela, se inició mediante la convocatoria, por parte del Jefe de Estado, de un referéndum consultivo para que el pueblo se pronunciase sobre la convocatoria de una Asamblea Nacional Constituyente....(pero) Tales circunstancias iniciales se debieron a la ausencia en la Carta de 1961 de mención alguna de esta modalidad de revisión constitucional (sensu lato), lo que hizo necesaria la debida consulta interpretativa ante la antigua Corte Suprema de Justicia. La situación constitucional actual es totalmente diferente. En efecto, como consecuencia del proceso de producción constituyente originaria, se estableció en el Título IX de la Carta de 1999, tres modalidades de "revisión" constitucional: la enmienda, la reforma y la Asamblea Nacional Constituyente. (Tribunal Supremo de Justicia de Venezuela, 2017)

En segundo lugar, el TSJ dijo que, si bien en la Constitución de 1999 se recogía la convocatoria a una Constituyente, nada se decía en absoluto sobre la necesidad de un referéndum para convocar la misma. De hecho, acudiendo al Diario de Sesiones de la Asamblea Constituyente de 1999, citó que, si bien hubo una propuesta en tal sentido, la misma fue rechazada por la mayoría de constituyentistas que, aun reconociendo que el titular del poder constituyente era el pueblo y solo el pueblo, otorgaron la iniciativa de convocatoria al presidente, a la Asamblea Nacional, a las asambleas territoriales y, en última instancia, al propio pueblo (siempre que lo solicitase un $15 \%$ del censo nacional, algo nada fácil).

...no hay previsión alguna sobre un referéndum acerca de la iniciativa de convocatoria de una Asamblea Nacional Constituyente. Por otra parte, al consultar el contenido de la sesión 41 del 9 de noviembre de 1999, en el Diario de la Constituyente, esta Sala observó que, en el desarrollo del debate correspondiente, la propuesta del Constituyente Manuel Quijada de que el pueblo pudiera convocar a la Asamblea Constituyente mediante un referéndum, fue negada. (Tribunal Supremo de Justicia de Venezuela, 2017)

Hemos de matizar que, en nuestra opinión, para llegar a la misma conclusión, más relevante que el rechazo a la propuesta del constituyente Tejada resulta el análisis del debate constituyente en segunda votación, donde se puede comprobar que mayoritariamente se optó por un poder constituyente libre, y donde se retiró, por regular excesivamente dicho poder, la propuesta de referéndum preceptivo de convocatoria que había sido aceptada en primera votación (Compains Silva, 2018).

En tercer lugar, la sala estableció que, vistas las circunstancias sobrevenidas, y ante la aguda crisis que vivía el país, el Gobierno tenía toda la legitimidad para convocar a una Asamblea Constituyente para poner de acuerdo con el país en torno a un nuevo contrato social.

Ahora bien, ciertamente el artículo 71 eiusdem contempla la posibilidad opcional o facultativa de convocar a referendo consultivo las "materias de especial trascendencia nacional"; sin embargo, existen circunstancias objetivas sobrevenidas que ambientan el proceso de instalación de la Asamblea Nacional Constituyente, como es la aguda situación de la crisis política actualmente enfrentada y que ha provocado el decreto de un estado de excepción no concluido aún, que ha motivado la 
toma de decisiones genéricas, expeditas y de profundidad constitucional, dentro de la cuales, por iniciativa del Presidente de la República se ha resuelto iniciar la convocatoria a una Asamblea Nacional Constituyente, que pueda en condiciones pacíficas poner de acuerdo al país en un nuevo Contrato Social, sin hacer uso en esta oportunidad, por tales circunstancias, de lo previsto en el citado artículo 71. Efectivamente, una de las razones fundamentales de que se hiciese necesario convocar un referéndum consultivo bajo la vigencia del texto constitucional de 1961, es que en el mismo no estaba contenida esta modalidad de revisión constitucional (sensu lato). Por el contrario, la Carta de 1999 la contempla expresamente, aunque para conservar su característica de poder constituyente originario (y no constituyente derivado — enmienda y reformao constituido), solo se precisa la iniciativa para su convocatoria, la prohibición de que los poderes constituidos puedan impedir u objetar las decisiones constituyentes (art. 349) y el límite al producto de sus actuaciones o deliberaciones: el carácter republicano del Estado, la independencia (soberanía), la paz, la libertad, el mantenimiento de los valores, principios y garantías democráticas, y la progresividad de los derechos humanos. (Tribunal Supremo de Justicia de Venezuela, 2017, art. 350)

Y en cuarto y último lugar, dijo que, aun siendo cierto, como no podría ser de otra manera, que la Constitución reconoce la soberanía popular, lo cierto era que dicha soberanía se podía ejercer directa o indirectamente a través de representantes, con lo cual el presidente estaba perfectamente capacitado para dicha convocatoria.

Claro está, lo expuesto no significa que el modelo de democracia participativa excluye la representación. Ello implicaría la desaparición del Estado-aparato, que es imprescindible para la gestión diaria de los asuntos públicos. Como refiere Enrique Dussel, la democracia participativa y la representativa no son términos antitéticos o contradictorios: "Deben ser articulados dialécticamente, de manera que un término enriquezca al otro y se definan mutuamente”....Ahora bien, la representación que, como advertimos, fue la regla en la Constitución de 1961, no deja de ser democrática y junto con los medios directos de ejercicio de la soberanía que ofrece la Constitución de 1999, constituyen los rasgos característicos del modelo constitucional venezolano. El artículo 347, cuya interpretación se solicita, debemos necesariamente articularlo con el artículo 348, ambos del texto constitucional. En efecto, el pueblo de Venezuela es el depositario del poder constituyente originario y, en tal condición, y como titular de la soberanía, le corresponde la convocatoria de la Asamblea Nacional Constituyente. Pero la iniciativa para convocarla le corresponde, por regla general, a los órganos del Poder Público (el Presidente o Presidenta de la República en Consejo de Ministros; la Asamblea Nacional, mediante acuerdo de las dos terceras partes de sus integrantes; y los Concejos Municipales en cabildos, mediante el voto de las dos terceras partes de los mismos) quienes ejercen indirectamente y por vía de representación la soberanía popular. La única excepción de iniciativa popular de convocatoria es la del quince por ciento de los electores inscritos y electoras inscritas en el Registro Civil y Electoral. De tal manera que, el artículo 347 define en quien reside el poder constituyente originario: en el pueblo como titular de la soberanía. Pero el artículo 348 precisa que la iniciativa para ejercer la convocatoria constituyente le corresponde, entre otros, al "Presidente o Presidenta de la República en Consejo de Ministros”, órgano del Poder Ejecutivo, quien actúa en ejercicio de la soberanía popular. (Tribunal Supremo de Justicia de Venezuela, 2017)

Por todo ello, la sala terminó estableciendo:

En los términos expuestos anteriormente, la Sala considera que no es necesario ni constitucionalmente obligante, un referéndum consultivo previo para la convocatoria de una Asamblea Nacional Constituyente, porque ello no está expresamente contemplado en ninguna de las disposiciones del Capítulo III del Título IX. (Tribunal Supremo de Justicia de Venezuela, 2017)

Como es sabido, y aun cuando esta sentencia fue objeto de críticas e incluso nuevos recursos por parte de la fiscalía (Prodavinci, 2017), la "Constituyente Ciudadana" se abrió camino, fue elegida una Asamblea Constituyente con plenos poderes, y las expresiones de violencia opositora que se vieron, sobre todo en la primera mitad de 2017, desaparecieron tan pronto como esta comenzó con su labor.

\section{El proceso soberanista en Catalunya (2010-2018)}

Como se afirmaba en la introducción de este escrito, Catalunya está inmersa en un proceso soberanista desde hace años. La sentencia del Tribunal Constitucional sobre el Estatut de Autonomía de Catalunya (Gobierno de España, 2010) agotó la paciencia de millones de catalanes (Villaró, 2010, pp. 22-29) que 
llevaban años descontentos con el trato discriminatorio que les daba el Gobierno de España (tanto en lo que a su lengua, educación y cultura propias se refiere, como a políticas sociales, transportes, infraestructuras y un largo etc.). Millones de catalanes, hasta esa fecha, creían mayoritariamente que era posible el desarrollo de su autogobierno en el marco autonómico, y por lo tanto descartaban mayoritariamente la idea de la independencia (“Romeva”, 2019; Canal, 2018).

Los acontecimientos se sucedieron de forma acelerada: tras la sentencia, las calles se llenaron de manifestantes (primero contra la sentencia, luego por la soberanía e independencia); se organizaron consultas populares; se quemaron fotos del rey; se retiraron banderas españolas; el independentismo subió meteóricamente, tanto en las encuestas como en las elecciones; y lo que resulta fundamental, ello cambió la posición política de quienes tradicionalmente habían defendido la vía autonomista para el autogobierno ( $\mathrm{CiU}$, el centro-derecha catalanista). La alternativa política preferida para una significativa parte de la sociedad catalana pasaba a ser la independencia.

Desde entonces, atendiendo a lo que de forma muy mayoritaria viene demandando la ciudadanía de Catalunya, las instituciones catalanas han intentado organizar una consulta o referéndum al objeto de permitir a la ciudadanía catalana decidir su futuro libremente 9 . Sin embargo, y a diferencia de la actitud del Reino Unido con Escocia, el Gobierno español se ha negado a dialogar para acordar los términos de un referéndum, y ha acudido permanentemente al Tribunal Constitucional para frenarlo, alegando que está viciado de inconstitucionalidad. Un Tribunal Constitucional que, en opinión de buena parte de la doctrina, hace años que perdió ya toda su auctoritas constitucional ${ }^{10}$ por haberse convertido en el brazo judicial del gobierno.

La Constitución española ampara el derecho fundamental a la participación política y la LO 2/1980 (Gobierno de España, 1980) regula distintas posibilidades de referéndum, que ha de ser autorizado por el Gobierno al ser materia de su exclusiva competencia (art. 149.1.32CE). Incluso podría transferir dicha competencia a Catalunya vía art. 150.2CE.

Sin embargo, el Gobierno ha manifestado reiteradamente que dicho referéndum nunca se va a celebrar, y lleva años acudiendo a los Tribunales para prohibirlo, disfrazando de problema de legalidad lo que no es sino un problema político que debiera solucionarse a través del diálogo y la negociación. De hecho, no se ha limitado a perseguir el referendo, sino que ha recurrido decenas de leyes aprobadas en el Parlament, que nada tenían que ver con el proceso soberanista, pero que perfilaban un proyecto político alternativo e incluso antagónico al suyo (en su mayoría, leyes de contenido social progresista).

Los intentos por parte catalana para poder celebrar el referendo de forma acordada han sido muchos. Ya en el Estatut de 2006 se había recogido en su artículo 122 la competencia para organizar consultas, con excepción de lo previsto en el mencionado art. 149.1.32CE. El TC, sin embargo, restringió su interpretación y cerró las puertas a dicha posibilidad con su sentencia (Gobierno de España, 2010) de 28 de junio de 2010 (Llorens Ferrer, 2013, p. 167).

El 16 de enero de 2014, el Parlamento de Catalunya aprobó pedir formalmente al Congreso de los diputados autorización para celebrar el referéndum previsto para el 9 de noviembre de $2014^{11}$. Pero el 8 de abril, el Congreso de los diputados, en el que el PP tenía mayoría absoluta, la rechazó por amplia mayoría (Garea, 2014).

Cerrada dicha posibilidad, la otra opción era legislar la consulta en Catalunya, y así lo hicieron, al aprobar la Ley de consultas no refrendarias (Comunidad Autónoma de Cataluña, 2014), ${ }^{12}$ el 19 de septiembre de 2014. Contaban, además, con el aval del Consejo de Garantías Estatutarias de Catalunya, que es el órgano autonómico que vela por el cumplimiento de la legalidad de las resoluciones del Parlament. Basándose en esta ley fue que el Govern de la Generalitat convocó, vía decreto, una consulta popular para el 9 de noviembre de 2014.

El Gobierno de España, una vez más, interpuso recurso de inconstitucionalidad contra la citada Ley y contra el Decreto de convocatoria, hecho con base en la misma, recurso que fue admitido a trámite en sesión 
extraordinaria celebrada por el TC, por lo que la ley y el decreto quedaron inmediatamente en suspenso (Gobierno de España, 2014) ${ }^{13}$.

Se planteó, entonces, una consulta alternativa, llamada proceso participativo, que sería llevada a cabo por voluntarios, utilizando el registro de habitantes de Catalunya en lugar del censo oficial. Pero esta consulta también fue impugnada por el Gobierno y suspendida por el TC, alegando una vez más que Catalunya carecía de competencias en dicha materia. El Govern, sin embargo, anunció que la consulta seguía adelante, y así, finalmente se celebró, con el espectacular resultado de más de dos millones de votos en una consulta que había sido prohibida por el Tribunal Constitucional.

En 2015 se celebraron elecciones autonómicas que fueron presentadas como plebiscitarias (el voto a los partidos independentistas contaría como un sí a la independencia). Nuevamente las fuerzas independentistas obtuvieron una amplia mayoría en representantes parlamentarios que les permitió formar gobierno, si bien el sí a la independencia no quedaba claro en número de votos, ya que había una fuerza política (Cat Síque es pot, de la que era parte Podemos) que no se alineó ni con el independentismo ni con el unionismo.

Por ello, los partidos que suscribieron el acuerdo de Gobierno (Junts Pel Sí y la Candidatura de Unitat Popular), en lugar de proclamar inmediatamente la independencia, acordaron poner en marcha el proceso de desconexión con el Estado español e ir aprobando en ese espacio de tiempo la legislación que pudiese hacer posible proclamar la república. Así, en septiembre de 2017, aprobaron las leyes de transitoriedad jurídica y del referéndum, ambas, como ya se ha dicho, recurridas por el Gobierno de España e inmediatamente suspendidas y derogadas por el TC (Gobierno de España, 2017a, 2017b).

Lo cierto es que los gobernantes catalanes no acataron estas prohibiciones del TC ni cedieron ante las amenazas, y por aquellos días, ganaron la batalla por la eficacia de las normas (Tajadura, 2017), ya que sus leyes, aun no siendo válidas, sí que fueron eficaces, pues buena parte del pueblo de Catalunya las cumplió. Ello hizo posible que el 1 de octubre se celebrase con notable éxito el referéndum de autodeterminación de Catalunya. La Guardia Civil y la Policía Nacional se emplearon a fondo para intentar evitarlo. Secuestraron urnas, agredieron, ante las cámaras de TV de medio mundo, a miles de personas que pacíficamente resistían ante una prohibición que consideraban injusta, pero no consiguieron su objetivo. Nuevamente, más de 2.300.000 catalanes salieron a desafiar al Estado con un "arma" plenamente democrática: el voto.

Sin embargo, el Gobierno del Partido Popular, lejos de abrirse a la negociación y el acuerdo, lo único que hizo fue endurecer su política. Por una parte, suspendiendo de facto la autonomía de Catalunya, acordando la inédita aplicación del artículo 155 CE (Gobierno de España, 2017c) ${ }^{14}$. Por otra, al ordenar a la Fiscalía abrir una causa general contra los líderes civiles, políticos e institucionales del procés (causa que comenzó en la Audiencia Nacional y que actualmente se desarrolla en el Tribunal Supremo, y que ha llevado a la cárcel o al exilio a la totalidad de miembros del Govern, incluido el President Carles Puigdemont).

En diciembre de 2017, ante la crisis abierta por la aplicación del art. 155 CE, el Gobierno de España convocó elecciones autonómicas en Catalunya, con la esperanza de que una victoria de los partidos unionistas pudiese cerrar la crisis catalana. Sin embargo, las fuerzas independentistas volvieron a vencer, y aun cuando no se les permitió nombrar presidente oficialmente a Carles Puigdemont, lo nombraron presidente legítimo y designaron oficialmente a Joaquim Torra.

\section{Conclusiones}

Las Constituciones y los Tribunales Constitucionales que los "protegen" son herramientas básicas de los sistemas democráticos actuales. La misión fundamental de todo TC es garantizar la supremacía de la Constitución como norma, velando porque los poderes del Estado respeten el ordenamiento jurídico y no vulneren los derechos fundamentales de los ciudadanos establecidos en esta, incluso, aunque tengan el respaldo de una mayoría ciudadana para hacerlo. 
Es cierto que democracia es el gobierno de la mayoría, pero no vale todo en nombre de esta. Se trata de evitar lo que se conoce como "tiranía de la mayoría" y proteger a las minorías, sean estas nacionales, étnicas, lingüísticas, políticas, de orientación sexual, etc.

En ese sentido, es perfectamente legítimo, en sistemas democráticos, cuando se forma parte de una minoría, acudir al Tribunal Constitucional si los poderes públicos han vulnerado nuestros derechos. Lo que no resulta tan legítimo es acudir a este para intentar frenar un proyecto político legítimo, democrático y respetuoso con los derechos de todos y todas, simplemente porque "no es el nuestro".

En nuestra opinión, eso es precisamente lo que ocurrió durante los procesos constituyentes latinoamericanos de la pasada década, e incluso (aunque de forma más limitada) en el proceso constituyente que se viene desarrollando a día de hoy en Venezuela. Las élites tradicionales (y sus seguidores) pretendieron frenar en los Tribunales lo que no eran capaces de frenar con votos: el avance y profundización en los procesos de cambio latinoamericanos.

En Venezuela, Chávez había llegado a la presidencia del gobierno en 1999 defendiendo la celebración de un referéndum consultivo para que el pueblo convocase (o no) una Asamblea Constituyente con objeto de refundar la república y establecer una democracia social y participativa. Las fuerzas políticas afines al régimen puntofijista se opusieron a dicha convocatoria, alegando que en la Constitución de 1961 no había previsión alguna sobre una Asamblea Constituyente, pero no consiguieron su objetivo.

La Corte Suprema de Justicia, haciendo suya la doctrina clásica del poder constituyente, la que nace de la tradición revolucionaria norteamericana y francesa, estableció que el poder constituyente no tenía límites en el ordenamiento jurídico vigente, y que tenía primacía sobre los poderes constituidos del Estado, ya que su legitimidad nacía directamente de la soberanía popular. Por ello, no vio ningún obstáculo legal en el referéndum que convocó el presidente con base en el art. 4 de la Constitución de 1961 y el 181 de la Ley de Sufragio y Participación Política.

En el caso de Ecuador, el presidente Palacio planteó, en 2005, hasta en dos ocasiones, una consulta ciudadana muy similar a la de Chávez, con base en el artículo 104 de la Constitución, que le permitía consultar a la ciudadanía cuestiones de especial trascendencia nacional. Sin embargo, el Tribunal Supremo Electoral, fuertemente influido por las fuerzas políticas tradicionales y haciendo oídos sordos a la doctrina mayoritaria sobre el poder constituyente, denegó dicha posibilidad por no estar prevista entre los mecanismos de reforma de la Constitución de 1998.

Se tuvo que cambiar la correlación de fuerzas en el país para que dicha consulta fuese posible. Así, meses más tarde, el presidente Correa asumió la presidencia y de inmediato convocó por decreto una consulta muy similar a la propuesta por Palacio. Aún con debate y dificultades, la consulta finalmente pudo celebrarse y el proceso constituyente desarrollarse.

En Bolivia, ya en 2001, el Tribunal Constitucional había denegado la posibilidad de hacer una consulta sobre la Asamblea Constituyente al estilo de Venezuela, por falta de previsión constitucional. Las fuerzas políticas tradicionales, conservadoras del sistema, recelaban de dicha posibilidad, aunque finalmente la necesidad de cambio se impuso. Eso sí, se reconoció la Asamblea Constituyente como mecanismo de reforma derivado de la Constitución vigente, lo cual la privó de carácter originario y de tener plena influencia sobre el resto de poderes constituidos.

Como en la Constitución se reguló que la ley de convocatoria tenía que ser aprobada por mayoría de dos tercios, las fuerzas conservadoras, en minoría en el Congreso, impusieron que las decisiones de la Asamblea también se adoptasen por mayoría de dos tercios, de forma que en la práctica se garantizaron un derecho de veto que no habrían tenido en una Asamblea Constituyente originaria.

Es decir: las fuerzas tradicionales se valieron del ordenamiento jurídico vigente para limitar el cambio político que venía, aun cuando dicho cambio era plenamente respetuoso con los derechos humanos y de las minorías. 
En lo que respecta a la convocatoria a una nueva Asamblea Constituyente, hecha en 2017 por el presidente Nicolás Maduro, con base en el art. 348 de la Constitución, la oposición también acudió a la justicia para intentar frenar dicha convocatoria. Su alegato principal fue que solo el pueblo puede convocar dicha Asamblea, tal y como se hizo en 1999.

Lo cierto es que el TSJ no les dio la razón, y estableció que el presidente tenía plena legitimidad constitucional para realizar dicha convocatoria, sin que fuera preceptivo convocar un referéndum al respecto. Un análisis exhaustivo de las actas de debate de la ANC de 1999 permite constatar que la idea de imponer un referéndum preceptivo de convocatoria a la ANC fue descartada por los constituyentes.

Por último, en cuanto a Catalunya, que se encuentra en unas coordenadas no solo geográficas sino políticas ciertamente diferentes, está claro que el problema que vemos actualmente no es, en esencia, jurídico sino político, de falta de voluntad política por parte del Gobierno español para que el pueblo catalán sea consultado sobre su futuro. Como se ha dicho, existen o pueden existir herramientas constitucionales suficientes para hacer un referéndum legal y acordado, pero el Gobierno español, sea del PP o del PSOE, lo impide valiéndose de su particular lectura de la Constitución Española y de la influencia que tiene en el Tribunal Constitucional.

En ese sentido, hay que señalar que el procés catalán ha sido escrupulosamente pacífico y democrático, y que en ningún caso están en peligro los derechos fundamentales de la minoría unionista. De hecho, el propio presidente del Gobierno ya quedó en absoluto ridículo en una entrevista de radio, cuando dijo que en caso de que Catalunya fuese independiente, la ciudadanía catalana perdería su derecho a la nacionalidad española y a la ciudadanía europea. Nada de ello puede ocurrir, porque los españoles de origen no pueden perder su nacionalidad, y, por tanto, al seguir teniendo nacionalidad española, seguirían conservando la ciudadanía europea (Onda Cero, 2015).

El punto común a los casos analizados sería que, en todos ellos, las élites conservadoras del sistema se han valido de la Constitución vigente para intentar frenar en los Tribunales las grandes transformaciones políticas que no podían frenar con votos.

\section{Referencias}

Aguiar de Luque, L., y Reviriego Picón, F. (2006). Implicaciones constitucionales del giro político en algunos países latinoamericanos (2005-2007). Cuadernos de Derecho Público, 27, 237.

Ávila Santamaría, R. (2008). El neoconstitucionalismo transformador. El estado de derecho y la Constitución. Abya Yala.

Ávila Santamaría, R. (2011). El neoconstitucionalismo transformador. El Estado de Derecho y la Constitución de 2008. Abya-Yala.

Blanco Valdés, R. (2009). La politización de la Justicia. Letras Libres, 97, 47-70.

Brewer-Carías, A. (1999). Poder Constituyente originario y Asamblea Nacional Constituyente. Editorial Jurídica Venezolana.

Brewer-Carías, A. (2009). El inicio del proceso constituyente en Ecuador en 2007 y las lecciones de la experiencia venezolana de 1999. En J. M. Serna de la Garza (coord.), Procesos constituyentes contemporáneos en América Latina: tendencias y perspectivas(pp. 333-405). Unam.

Brewer-Carías, A., y García Soto, C. (comps.). (2017). Estudios sobre la Asamblea Constituyente y su inconstitucional convocatoria en 2017. Editorial Jurídica Venezolana.

Canal, J. (2018). Entre el autonomismo y la independencia: nacionalismo, nación y procesos de nacionalización en Cataluña (1980-2015). En I. Sepúlveda Muñoz (ed.), Nación y nacionalismos en la España de las Autonomias (pp. 77-108). BOE.

Compains Silva, E. (2016). Botere konstituziogilea latinaomerikar konstituzionalismo berrian. Venezuela, Bolivia eta Ekuadorreko azken prozesu konstituziogileen analisi konparatu bat. IVAP.

Compains Silva, E. (2018). Venezuela: el debate sobre la legitimidad constitucional de la convocatoria a la Asamblea Nacional Constituyente realizado por el Presidente Nicolás Maduro el 1 de mayo de 2017. RVAP, 111, 249-269. 
Comunidad Autónoma de Cataluña. (2013, 17 de diciembre). Butlletí Oficial del Parlament de Catalunya, 221. http s://www.parlament.cat/document/bopc/52291.pdf

Comunidad Autónoma de Cataluña. (2014, 26 de septiembre). Ley 10/2014 de 26 de septiembre, de consultaspopulares no refrendarias y otras formas de participación ciudadana (derogada).

Comunidad Autónoma de Cataluña. (2017a, 6 de septiembre). Ley 19/2017 de 6 de septiembre, de referéndum de autodeterminación.

Comunidad Autónoma de Cataluña. (2017b, 8 de septiembre). Ley 20/2017 de 8 de septiembre, de transitoriedad jurídica y fundacional de la República.

Congreso Nacional del Ecuador. (2007a, 13 de febrero). Resolución del Congreso R-28-038 de 13 de febrero de 2007.

Congreso Nacional del Ecuador. (2007b, 6 de marzo). Resolución del Congreso R-28-053 de 6 de marzo de 2007.

Corte Suprema de Justicia de Venezuela. (1999a, 19 de enero). Sentencias de la Sala Politico Administrativa de la Corte Suprema de Justicia de Venezuela de 19 de enero de 1999.

Corte Suprema de Justicia de Venezuela. (1999b, 14 de octubre). Sentencia del Pleno de la Corte Suprema de Justicia de Venezuela de 14 de octubre de 1999.

Curcio Curcio, P. (2017). La mano visible del mercado. Guerra económica en Venezuela. Ediciones MinCi.

De La Fuente Jeria, J. (2008). Los alrededores de la Asamblea Constituyente. Tinkazos, 11(23-24), 85-100.

Echeverría, J. (2007). La democracia difícil: neopopulismo y antipolítica en Ecuador. Iconos, Revista de Ciencias Sociales, $27,27-35$.

El 82\% de los catalanes creen que la solución es un referéndum de independencia pactado. (2017, 24 de septiembre). Público. http://www.publico.es/politica/encuesta-catalunya-82-catalanes-creen-solucion-referendum-indepen dencia-pactado.html

Errejón Galván, I. (2008). La crisis estatal de Bolivia. De la llegada al Gobierno del MAS a los referendos revocatorios (Papeles de Trabajo América Latina en el siglo XXI). CEPS.

Errejón Galván, I. (2009). La revolución siempre incompleta. Perspectivas políticas tras el referéndum constitucional. Viento Sur, 102. https://cdn.vientosur.info/VScompletos/Bolivia\%20102.pdf

Fresneda, C. (2014). Cameron: 'No me arrepiento de haber accedido al referéndum'. El Mundo. https://www.elmun do.es/internacional/2014/09/17/5419599cca474198738b457a.html

Gaceta Constituyente. (1999, 3 de agosto).Diario de Sesiones, 3 de agosto 1999. Imprenta del Congreso de la República. Garea, F. (2014, 8 de abril). La Constitución frena la consulta. El País.

Garrido, A. (1999). La constituyente en el marco revolucionario chavista. En J. M. Casal (coord.), El debate constituyente en Venezuela: ideas para una nueva Constitución. Fondo Editorial Nacional.

Gobierno de Bolivia. (1967). Constitución Boliviana de 1967.

Gobierno de Bolivia. (2002, 1 de agosto). Ley 2410 de necesidad de reforma de la Constitución, de 1 de agosto de 2002.

Gobierno de Bolivia. (2004, 20 de febrero). Ley 2631 de reforma constitucional, de 20 de febrero de 2004.

Gobierno de Bolivia. (2006, 6 de marzo). Ley Especial 3364 de 6 de marzo de 2006. Ley de convocatoria a la Asamblea Constituyente.

Gobierno de Bolivia. (2008a, 21 de octubre). Ley 3941 de 21 de octubre de 2008, de interpretación del artículo 232 de la Constitución.

Gobierno de Bolivia. (2008b, 21 de octubre). Ley 3942 de 21 de octubre de 2008, de Referéndum dirimitorio y refrendatorio de proyecto de Constitución Política del Estado.

Gobierno de Bolivia. (2009). Constitución Boliviana de 2009.

Gobierno de España. (1978). Constitución Española de 1978.

Gobierno de España. (1980, 18 de enero). LO 2/1980 de 18 de enero, sobre las distintas modalidades de referéndum.

Gobierno de España. (2010, 28 de junio). STC 28 de junio de 2010 sobre Estatut de Autonomía de Catalunya. Sentencia del Tribunal Constitucional 31/2010 de 28 de junio de 2010 sobre Estatut de Autonomia de Catalunya. https:// boe.es/diario_boe/txt.php?id=BOE-A-2010-11409 
Gobierno de España. (2014, 27 de septiembre). Providencia de Impugnación de disposiciones autonómicas (titulo $V$ LOTC) n. ${ }^{\circ}$ 5830-2014, contra el Decreto del Presidente de la Generalitat de Cataluña 129/2014, de 27 de septiembre, de convocatoria de consulta popular no referendaria sobre el futuro politico de Cataluña, y sus Anexos.

Gobierno de España. (2017a, 17 de octubre). STC 114/2017 de 17 de octubre de 2017 sobre Ley de referéndum de autodeterminación de Catalunya. https://www.boe.es/diario_boe/txt.php?id=BOE-A-2017-12206 y

Gobierno de España. (2017b, 8 de noviembre). STC 124/2017 de 8 de noviembre de 2017, sobre Ley de transitoriedad jurídica y fundacional de la República. https://www.boe.es/diario_boe/txt.php?id=BOE-A-2017-13228

Gobierno de España. (2017c, 21 de octubre). Orden PRA/1034/2017, de 27 de octubre, por la que se publica el Acuerdo del Consejo de Ministros de 21 de octubre de 2017. https://www.boe.es/diario_boe/txt.php?id=BOE-A-2017-1 2328

Gobierno de Venezuela. (1961). Constitución Venezolana de 1961.

Gobierno de Venezuela. (1998). Ley Orgánica de Sufragio y Participación Politica de 1998.

Gobierno de Venezuela. (1999). Constitución de la República Bolivariana de Venezuela de 1999.

Gobierno del Ecuador. (1998). Constitución Ecuatoriana de 1998.

Gobierno del Ecuador. (2000, 11 de julio). Ley Orgánica de elecciones de 11 de julio de 2000.

Gobierno del Ecuador. (2005a, 17 de octubre). Decreto Ejecutivo n. ${ }^{\circ} 705$, de 17 de octubre de 2005.

Gobierno del Ecuador. (2005b, 20 de octubre). Resolución del Tribunal Supremo Electoral de 20 de octubre de 2005.

Gobierno del Ecuador. (2005c, 30 de noviembre). Decreto Ejecutivo n. ${ }^{\circ} 893$ de 30 de noviembre de 2005.

Gobierno del Ecuador. (2005d, 16 de diciembre). Resolución PLE-TSE-1-4-12-200. Registro Oficial n. ${ }^{\circ} 167$ del 16 de diciembre de 2005.

Gobierno del Ecuador. (2007a, 15 de enero). Decreto Ejecutivo n. ${ }^{\circ} 2$ de 15 de enero de 2007.

Gobierno del Ecuador. (2007b, 23 de enero). Decreto Ejecutivo n. ${ }^{\circ} 54$ de 23 de enero de 2007.

Katz, C. (2017). La izquierda frente a Venezuela. Alainet. https://www.alainet.org/es/articulo/186111

La Vanguardia. (2017, 31 de agosto). El gobierno prepara con el TC una suspensión exprés. https://www.lavanguardia. com/vida/20170830/43927866089/portada-de-la-vanguardia-del-jueves-31-de-agosto-de-2017.html

Llorens Ferrer, M. (2013). La consulta popular como mecanismo para revitalizar el urbanismo democrático. Revista catalana de dret públic, 46, 161-181.

Márquez Ferrer, V. (1998). Verdades y mentiras de la Constituyente. En R. Combellas (coord.), Constituyente, Aportes al debate. Fundación Konrad Adenauer.

Martínez Dalmau, R. (2008). De Sucre a Oruro, pasando por Santa Cruz. Revista IUS, 2(21). https://doi.org/10.35 487/rius.v2i21.2008.261

Muñoz López, P. (2006, enero). De abril a diciembre, el recurrente simulacro de la Reforma Política. Iconos, Revista de Ciencias Sociales, 24, 9-15.

Onda Cero. (2015, 23 de septiembre). Mariano Rajoy sobre la nacionalidad española en el caso de independencia de Catalunya [video]. YouTube. https://www.youtube.com/watch?v=9QBRSry3uwk

Peláez, V. (2017). El terrorismo y la guerra mediática contra Venezuela. Aporrea. https://www.aporrea.org/medios/a 248972.html

Pérez-Loose, H. (2009). Ecuador y la metamorfosis constituyente. En J. M. Serna de la Garza (coord.), Procesos constituyentes contemporáneos en América Latina: tendencias y perspectivas (pp. 225-261). Unam.

Prodavinci. (2017, 1 de junio). ¿Qué dijo la Fiscal Luisa Ortega sobre la convocatoria a la Constituyente? https://historico.prodavinci.com/2017/06/01/actualidad/que-dijo-la-fiscal-luisa-ortega-sobrela-convocatoria-a-la-constituyente-monitorprodavinci-1/

Romero Jiménez, J. E. (2002). La nueva dinámica de poder en Venezuela: El MVR, Hugo Chávez y el proceso constituyente (1999). Clio, 25. http://clio.rediris.es/articulos/poder_venezuela.htm

Romeva: Todo arranca con la sentencia del Estatut, fue una ruptura emocional. (2019, 19 de febrero). El Diario. http s://www.eldiario.es/politica/Romeva-arranca-sentencia-Estatut-emocional_0_869663940.html 
Salgado Pasantes, H. (2009). El proceso constituyente en Ecuador. Algunas reflexiones. En J. M. Serna de la Garza (coord.), Procesos constituyentes contemporáneos en América Latina: tendencias y perspectivas (pp. 205-223). Unam.

Tajadura, J. (2017, 8 de septiembre). Validez y eficacia de la ley fundacional. El País.

Tribunal Constitucional de Bolivia. (2001, 17 de enero). Declaración Constitucional del Tribunal Constitucional de Bolivia 01/2001 del 17 de enero de 2001.

Tribunal Supremo de Justicia de Venezuela. (2017, 31 de mayo). Sentencia de la Sala Constitucional del TSJ n. ${ }^{\circ} 378$, de 31 de mayo de 2017.

Villaró, R. (2010). Cataluña se revela. Sentencia del TC sobre el Estatut. Cambio 16.

\section{Notas}

1 Art. 159.5 CE: "Los miembros del Tribunal son independientes e inamovibles en el ejercicio de su mandato".

2 El Act of Union de 1707, en virtud del cual los reinos de Escocia e Inglaterra dieron nacimiento al Reino Unido de Gran Bretaña, reza en su primer artículo que dicha unión es para siempre (forever after). Ello no supuso obstáculo alguno para que el primer ministro británico, James Cameron, al constatar la existencia de una mayoría favorable a la celebración de un referéndum en Escocia, acordase con Alex Salmond, primer ministro escocés, las bases para un referéndum de independencia. Como británico, Cameron quería que escocia permaneciese en el Reino Unido, pero como demócrata, no podía impedir que la nación escocesa decidiera libremente. Ver Fresneda (2014).

3 Casos estudiados en profundidad en la tesis doctoral de quien firma el presente trabajo; tesis redactada en euskera, que fue publicada por el Instituto Vasco de Administración Pública, dependiente del Gobierno Vasco: Compains Silva (2016).

4 Para Martínez Dalmau (2008) y Errejón Galván (2008) fue un grave error, ya que lo que se hizo para integrar y sumar a la oposición al proceso consiguió el efecto contrario, permitiéndole boicotearlo desde un principio.

5 Ley de interpretación del artículo 232 de la Constitución.

6 Ley de Referéndum dirimitorio y refrendatorio de proyecto de Constitución Política del Estado.

7 Art. 155: "Serán reprimidos con la destitución del cargo y la suspensión de los derechos políticos por el tiempo de un año: ...e) La autoridad, funcionario o empleado público extraños a la Organización Electoral que interfiere el funcionamiento de los organismos electorales".

8 Buena parte de la doctrina se manifestó también en contra de la convocatoria. Como muestran Brewer-Carías y García Soto (2017).

9 El apoyo a la consulta supera el 80\% según las encuestas. Ver "El 82\% de los catalanes" (2017).

10 Distintos autores se han pronunciado a lo largo de los últimos años sobre esta problemática. Por ejemplo, Blanco Valdés (2009).

11 "Proposta per a presentar a la Mesa del Congrés dels Diputats la Proposició de llei orgànica de delegació a la Generalitat de Catalunya de la competència per a autoritzar, convocar i celebrar un referèndum sobre el futur polític de Catalunya" (Comunidad Autónoma de Cataluña, 2013).

12 Ley de consultas populares no referendarias y otras formas de participación ciudadana (declarada inconstitucional por el TC).

13 "Providencia de Impugnación de disposiciones autonómicas (título V LOTC) n. ${ }^{\circ}$ 5830-2014, contra el Decreto del Presidente de la Generalitat de Cataluña 129/2014, de 27 de septiembre, de convocatoria de consulta popular no refrendaria sobre el futuro político de Cataluña, y sus Anexos".

14 Acuerdo del Consejo de Ministros para aplicar el artículo 155CE en Catalunya.

* Artículo de investigación. El presente trabajo ha sido realizado al amparo del Grupo de Investigación Consolidado del Sistema Universitario Vasco Derechos Fundamentales y la Unión Europea.

\section{Licencia Creative Commons CC BY 4.0}

Cómo citar este artículo: Compains Silva, E. (2020). La utilización de la constitución vigente como freno a grandes transformaciones políticas. Los casos de Venezuela, Bolivia, Ecuador y el reciente caso de Catalunya en el Reino de España. Papel Político, 25. https://doi.org/10.11144/Javeriana.papo25.ucvf 